\title{
Pulmonary function in tropical eosinophilia before and after treatment with diethylcarbamazine
}

\author{
M. S. NES A R A J A H \\ Department of Physiology, Faculty of Medicine, University of Sri Lanka, Colombo
}

\begin{abstract}
Nesarajah, M. S. (1975). Thorax, 30, 574-577. Pulmonary function in tropical eosinophilia before and after treatment with diethylcarbamaxine. Spirometric and lung volume measurements were carried out before and after treatment with diethylcarbamazine in 19 patients with tropical eosinophilia. The total lung capacity and vital capacity returned to or nearly to normal while the FEV, and PEFR, though improved, tended to remain below normal, indicating some residual airways obstruction especially in patients whose treatment began more than one month from the onset of symptoms. The time taken for the pulmonary function to return to normal with treatment was found to be much longer than for the clinical and haematological response.
\end{abstract}

Pulmonary function studies in patients with tropical eosinophilia have shown that during the early stages of the disease there is mild to moderate obstruction to the airways and that as the disease progresses there is, in addition, a restrictive ventilatory defect (Nesarajah, 1972). Diethylcarbamazine is the specific drug used in the treatment of patients suffering from this disease. Although there are several reports of the clinical improvement observed in such patients after treatment (Chaudhuri, 1956; Danaraj, 1958; Misra et al., 1959; Edirisinghe and Weerasinghe, 1963; Narang and Jain, 1966), objective assessment of such improvement is not equally well documented (Udwadia, 1967; Azad Khan et al., 1970). The present study was therefore undertaken to assess pulmonary function before and after treatment with diethylcarbamazine in patients with tropical eosinophilia in Sri Lanka.

\section{MATERIAL AND METHODS}

A group of 19 patients, 18 males and one female, was studied. All patients gave the typical clinical history, had circulating eosinophil counts of over $2000 / \mu$ l of blood, positive filaria complement fixation tests, and elevated erythrocyte sedimentation rates, and showed a clinical and haematological response to diethylcarbamazine, thereby satisfying the criteria recommended by Donohugh (1963) for the diagnosis of tropical eosinophilia. Before their entry into the study, none of these patients had been receiving any specific therapy for tropical eosinophilia. The duration of symptoms was les than one month in 10 patients and from one to five months in the remaining nine. The patients were accordingly divided into two groups-grouß A, with symptoms of less than one month's dura $\vec{F}$ tion, and group B, with symptoms of more tham one month's duration.

The lung volumes and expiratory flow rates. were measured using a Godart Pulmonet, Aik spirometer, and a Wright peak flow meter, as dese cribed in a previous paper (Nesarajah, 1972). The patients were treated with diethylcarbamazine $250 \mathrm{mg}$ three times a day for 7 days, and the above measurements were repeated after the course o $\$$ treatment was over. The erythrocyte sedimenta tion rate and the absolute eosinophil count were measured, and the filaria complement fixation test was also carried out both before and after. treatment in all patients.

In 17 of the patients the measurements were repeated within two weeks to six months aftep completion of the course of treatment, in one subject after eight months, and in one other subo ject 16 months after completion of the treatmento Although it was proposed to carry out thesథ measurements at regular intervals during the follow-up period, it was not possible to do so aso the patients would not report to the laboratory fort these tests once they felt better and left hospital. $\stackrel{?}{?}$

For purposes of comparison, the lung functiom tests were also carried out on a group of $3 E$ healthy subjects of comparable mean age and sexo 


\section{RESULTS}

As in the previous communication (Nesarajah, 1972), the values obtained for the vital capacity (VC), total lung capacity (TLC), forced expired volume in one second $\left(F E V_{1}\right)$, and peak expiratory flow rate (PEFR) in patients and controls were expressed as percentages of the predicted values for persons of European descent.

The changes observed in the lung volumes and expiratory flow rates before and after treatment for all patients are shown in Figs 1 and 2, and the mean values and standard deviations for the two groups of patients and the normal subjects are shown in the Table.

The mean values for the VC, FEV 1 and PEFR for both groups of patients before treatment were found to be significantly lower than for the normal subjects, while the mean values for TLC for either group was not different from that for the normal subjects. Following treatment, in both groups of patients there was a significant increase $(P<0.01)$ in the VC, FVC, FEV treatment VC for both groups of patients and the $\mathrm{FEV}_{1}$ for group A patients reached normal levels whereas the $\mathrm{FEV}_{1}$ for group $\mathrm{B}$ patients and the PEFR for both groups were still significantly lower than for the normal subjects.

The absolute eosinophil count, erythrocyte sedimentation rate, and the filaria complement fixation test had returned to normal in all the patients at the time the pulmonary function tests were repeated.

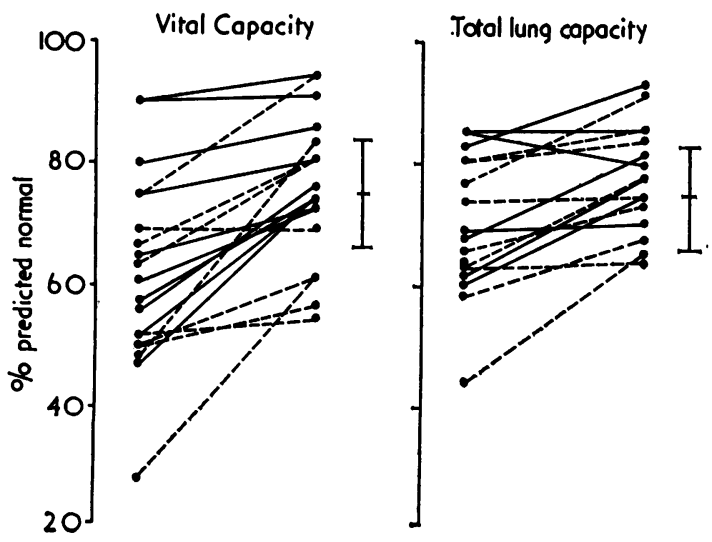

FIG. 1. Changes in lung volumes with treatment in group $A$ (unbroken lines) and group $B$ (broken lines) patients. Mean and standard deviation of control group to right. Group A-symptoms less than 1 month; group B-symptoms more than 1 month.

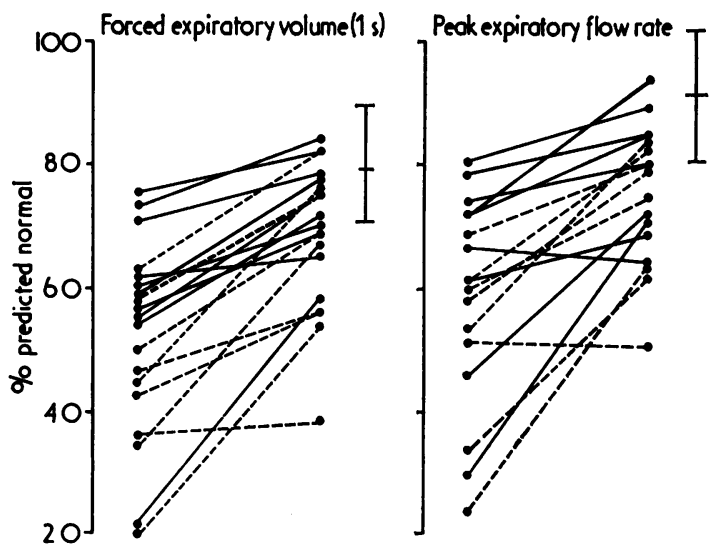

FIG. 2. Changes in expiratory flow rates with treatment in group $A$ (unbroken lines) and group $B$ (broken lines) patients. Mean and standard deviation of control group to right. Group A--symptoms less than 1 month; group B-symptoms more than 1 month.

\section{DISCUSSION}

Diethylcarbamazine is the specific drug used today in the management of patients with tropical pulmonary eosinophilia. It replaced the organic arsenicals as the drug of choice, because, though equally effective therapeutically, it produces none of the dangerous and sometimes fatal toxic effects commonly seen with arsenic therapy (Danaraj, 1958; Ganatra, Sheth, and Lewis, 1958; Shanker, Bhargava, and Shrivastava, 1960; Islam, 1964).

The cure rate with diethylcarbamazine therapy, as commonly gauged by amelioration of symptoms, disappearance of the lung signs, a clearing of the radiological picture, a return of the erythrocyte sedimentation rate to normal, and a decrease in the eosinophil count, ranges from about $80 \%$ to $100 \%$ in various series (Ganatra and Lewis, 1955; Danaraj, 1958; Ganatra et al., 1958; Shanker et al., 1960; Narang and Jain 1966; Azad Khan et al., 1970). Udwadia (1967) observed a poor response to treatment (and so a low cure rate) in patients with a long history and with fibrosis of the lung, and there is now evidence that some of the cases which do not respond to treatment may have a non-filarial aetiology (Joshi, Udwadia, and Gadgil, 1969). The present series was selected on the basis of a cure, as judged by amelioration of symptoms, absence of lung signs, decrease of the eosinophil count to below $1000 / \mu 1$, return of the erythrocyte sedimentation rate to normal, and a negative filaria complement fixation test. 
T A B L E

MEAN VALUES (AND STANDARD DEVIATIONS) FOR LUNG VOLUMES AND EXPIRATORY FLOW RATES FOR NORMAL SUBJECTS AND FOR PATIENTS, BEFORE AND AFTER TREATMENT

\begin{tabular}{|c|c|c|c|c|c|c|c|c|}
\hline \multirow[b]{2}{*}{ Group } & \multicolumn{2}{|c|}{ VC } & \multicolumn{2}{|c|}{ TLC } & \multicolumn{2}{|c|}{$\mathrm{FEV}_{1}$} & \multicolumn{2}{|c|}{ PEFR } \\
\hline & Before & After & Before & After & Before & After & Before & After \\
\hline Normal subjects & \multicolumn{2}{|c|}{$\begin{array}{c}77 \cdot 2 \\
(8 \cdot 7)\end{array}$} & \multicolumn{2}{|c|}{$\begin{array}{l}72 \cdot 3 \\
(7 \cdot 0)\end{array}$} & \multicolumn{2}{|c|}{$\begin{array}{l}78 \cdot 5 \\
(8 \cdot 5)\end{array}$} & \multicolumn{2}{|c|}{$\begin{array}{c}91 \cdot 0 \\
(11 \cdot 0)\end{array}$} \\
\hline $\mathbf{A}$ & $\begin{array}{c}66.6 \\
(15 \cdot 5) \\
<0.01\end{array}$ & $\begin{array}{l}79 \cdot 3 \\
(8 \cdot 4) \\
\text { NS }\end{array}$ & $\begin{array}{c}72 \cdot 8 \\
(10 \cdot 8) \\
\text { NS }\end{array}$ & $\begin{array}{l}78 \cdot 9) \\
(7 \cdot 1) \\
\text { NS }\end{array}$ & $\begin{array}{c}58 \cdot 1 \\
(15 \cdot 2) \\
<0 \cdot 001\end{array}$ & $\begin{array}{l}72 \cdot 4 \\
(8 \cdot 2) \\
\text { NS }\end{array}$ & $\begin{array}{l}63.8 \\
(16.5) \\
<0.001\end{array}$ & $\begin{array}{c}77.9) \\
(9.1) \\
<0.001\end{array}$ \\
\hline B & $\begin{array}{l}55.3 \\
(14.6) \\
<0.001\end{array}$ & $\begin{array}{c}70.6 \\
(13.9) \\
\text { NS }\end{array}$ & $\begin{array}{c}65 \cdot 7 \\
(12 \cdot 2) \\
\text { NS }\end{array}$ & $\begin{array}{c}73 \cdot 6 \\
(10 \cdot 0) \\
\text { NS }\end{array}$ & $\begin{array}{l}43.7 \\
(12.5) \\
<0.001\end{array}$ & $\begin{array}{c}63.1 \\
(13.1) \\
<0.001\end{array}$ & $\begin{array}{l}50.6 \\
(14.5) \\
<0.001\end{array}$ & $\begin{array}{l}70.9 \\
(12.0) \\
<0.001\end{array}$ \\
\hline
\end{tabular}

The individual values from which the mean and standard deviations have been calculated have been expressed as percentages of the predicted values for Europeans (see text).

Although Danaraj (1958), using different daily dosage schedules for treatment, observed that the clinical response was better with daily doses of 18 and $30 \mathrm{mg} / \mathrm{kg}$ body weight than with the smaller dose, several workers both in India (Patwari, 1958; Viswanathan and Krishnamurthi, 1958; Baker, Rajan, and Devadatta, 1959) and in Ceylon (Edirisinghe and Weerasinghe, 1963; Attygalle, 1970) have found that diethylcarbamazine in as small a daily dose as 5 to $8 \mathrm{mg} / \mathrm{kg}$ body weight given for about a week to 10 days is effective. Shanker and Gaur (1971) used different dosage schedules and observed that the cure rate was dependent upon the total quantity of drug administered irrespective of the period of therapy. These findings confirm the earlier observations of Ganatra and Lewis (1955). Shanker and Gaur (1971) and Danaraj (1958) have also observed that with higher daily doses the clinical response was quicker than with lower daily doses. In the present series the total amount of drug administered was about $5 \mathrm{~g}$ in a daily dosage of about $12 \mathrm{mg} / \mathrm{kg}$ body weight.

Although clinical improvement with diethylcarbamazine therapy usually starts in two to four days after the beginning of treatment and most patients are completely free of symptoms by the end of the second week, the haematological response takes slightly longer (Danaraj, 1958; Narang and Jain, 1966; Crofton and Douglas, 1969). From the present study it seems that the time taken for pulmonary function to return to normal, if it does, is much longer than for both the clinical and the haematological response.

Even though the VC had returned to normal levels in both groups, the improvement in the airways obstruction with treatment, though significant, was still incomplete, particularly in the group B patients. These observations are consistent with the findings of Udwadia and Joshi (1964) in two patients who were submitted to lung biopsies after a month's treatment with diethylcarbamazine. Both these patients were completel $\$$ free of symptoms after seven days' therapy, ye both patients had pathological changes in the lung even after a month of treatment. They therefore concluded that relief of symptoms is not neces $\mathrm{G}$ sarily associated with a clearing of the lung lesions and also that these may exist in the absence ob peripheral eosinophilia.

It has been shown that in the natural histor of the disease the earliest functional defect is an obstructive ventilatory defect and that a restric $\varrho$ tive defect is superadded as the disease progresses $\overrightarrow{\overrightarrow{0}}$ So in patients who have had the disease for some time the pulmonary pathology responsible for the obstruction is of longer duration than that respon? sible for the restriction. It is therefore not sur prising that with treatment the improvement in the VC, a decrease in which is of more recente origin, is more marked than the improvement in the FEV ${ }_{1}$ and PEFR. In this connection it is inter esting to note that Azad Khan et al. (1970) found that even though there was a considerable increase in the VC with treatment, it still remained below normal in most of their cases. A possible explana tion would be that their patients might have has. the disease for a longer period than those in the present series and therefore had a larger com ponent of irreversible pathological changes in the lung.

This research was supported by a grant from theे Wellcome Trust, UK.

\section{REFERENCES}

Attygalle, D. J. (1970). Formulatory Notes, 5, 3. Azad Khan, A. K., Patra, R. W. T., Banu, S. A., an Rabbee, M. F. (1970). Spirometry in tropicab pulmonary eosinophilia. British Journal Diseases of the Chest, 64, 107. 
Baker, S. J., Rajan, K. T., and Devadatta, S. (1959). Treatment of tropical eosinophilia. A controlled trial. Lancet, 2, 144.

Chaudhuri, R. N. (1956). Tropical eosinophilia. Journal of the Indian Medical Association, 27, 195.

Crofton, J. and Douglas, A. (1969). Respiratory Diseases. Blackwell Scientific Publications, Oxford.

Danaraj, T. J. (1958). The treatment of eosinophilic lung (tropical eosinophilia) with diethylcarbamazine. Quarterly Journal of Medicine, new series, $27,243$.

Donohugh, D. L. (1963). Tropical eosinophilia. New England Journal of Medicine, 269, 1357.

Edirisinghe, F. V. and Weerasinghe, P. (1963). A clinical study of 150 cases of tropical eosinophilia with special reference to the treatment of this condition with parenteral diethylcarbamazine citrate. Medicine and Surgery, 3, No. 12, 41.

Ganatra, R. D. and Lewis, R. A. (1955). Hetrazan in tropical eosinophilia. Indian Journal of Medical Sciences, 9, 672 .

- Sheth, U.K., and Lewis, R. A. (1958). Diethylcarbamazine (Hetrazan) in tropical eosinophilia. Indian Journal of Medical Research, 46, 205.

Islam, N. (1964). Tropical Eosinophilia. Anwara Islam, Chittagong.

Joshi, V. V., Udwadia, F. E., and Gadgil, R. K. (1969). Etiology of tropical eosinophilia. A study of lung biopsies and review of published reports.
American Journal of Tropical Medicine and Hygiene, 18, 231.

Misra, S. S., Nath, K., Shanker, A., and Prakash, S. (1959). Diethylcarbamazine (oral and parenteral therapy) in tropical pulmonary eosinophilia. Journal of the Indian Medical Association, 32, 232.

Narang, R. K. and Jain, S. C. (1966). Oral diethylcarbamazine in tropical pulmonary eosinophilia. British Journal of Diseases of the Chest, 60, 93.

Nesarajah, M. S. (1972). Pulmonary function in tropical eosinophilia. Thorax, 27, 185.

Patwari, I. B. (1958). Tropical eosinophilia. Current Medical Practice, 2, 604.

Shanker, A., Bhargava, R. K., and Shrivastava, B. N. (1960). Diethylcarbamazine in tropical pulmonary eosinophilia. British Medical Journal, 1, 100.

— and Gaur, K. J. (1971). Tropical eosinophilia: therapeutic observations. Indian Journal of Chest Diseases, 13, 155.

Udwadia, F. E. (1967). Tropical eosinophilia-a correlation of clinical, histopathologic and lung function studies. Diseases of the Chest, 52, 531 .

Viswanathan, M. and Krishnamurthi, M. (1958). Diethylcarbamazine citrate in tropical eosinophilia. Antiseptic, 55, 357.

Requests for reprints to: Dr. M. S. Nesarajah, Department of Physiology, Faculty of Medicine, University of Sri Lanka, Colombo. 